\title{
Measuring the mathematical problem solving and procedural skills of students in an Irish higher education institution - A pilot study
}

\author{
Fiona Faulkner ${ }^{1}$, Cormac Breen ${ }^{2}$, Mark Prendergast ${ }^{3 *}$ and Michael Carr ${ }^{4}$ \\ ${ }^{1}$ School of Hospitality, Tourism and Management, Technological University Dublin, Dublin, Ireland \\ ${ }^{2}$ School of Mathematical Sciences, Technological University Dublin, Dublin, Ireland \\ ${ }^{3}$ School of Education, University College Cork, Ireland \\ ${ }^{4}$ School of Multidisciplinary Technologies, Technological University Dublin, Dublin, Ireland. \\ For correspondence: fiona.faulkner@tudublin.ie
}

\begin{abstract}
:
In 2010 the Irish second level mathematics curriculum underwent a period of significant change when a new mathematics curriculum was introduced. Some preliminary research has been carried out into the impact, if any, that this mathematics curriculum is having on students mathematics performance which have suggested that students' procedural skills are declining year on year however their problem solving skills may have improved (Treacy and Faulkner 2015). Additional research in this area also highlighted that students willingness to engage in problem solving activities may have improved (Prendergast et al 2017). However preliminary analysis on the impact of the reformed mathematics curriculum, if any, on students' performance in higher education noted that further research was needed in this area to definitively establish what is happening. This research therefore aims to explicitly determine whether the procedural and problem solving skills of beginning undergraduates are changing over time as a result of the reformed mathematics curriculum introduced in second level education. A paper based diagnostic test designed and developed is used in an attempt to determine this. This paper will detail the piloting of this diagnostic test with a group of higher education students in the Irish context.
\end{abstract}

Keywords: diagnostic testing, procedural skills, problem solving skills, undergraduate maths education.

\section{Introduction}

The last decade has seen significant changes to mathematics education at second level in Ireland with the introduction of a new mathematics curriculum entitled 'Project Maths' (PM) being rolled out on a phased basis since 2010 (Prendergast et al., 2017). This change to mathematics education in Ireland was brought about with the intention of engaging students with problem solving activities which would elicit real understanding of mathematical content and promote engagement with the mathematical content being addressed in the classroom. This was to replace a previous system which focussed primarily on traditional procedural approaches to teaching mathematics which was predominately teacher centred (Hourigan and O'Donoghue 2007).

Irish students' poor performance on an international platform in mathematics (Humphreys 2015) was one of the main incentives to change the emphasis of the teaching and learning of mathematics in second level education. In addition longitudinal research published which detailed that Irish second level students' performance in basic mathematical skills on entry to third level education was in steady decline since 1998 contributed to the need for change in second level mathematics (Faulkner et al., 2010; Gill et al., 2010; Faulkner et al., 2014).

Although the introduction of PM in second level schools in Ireland is in its infancy, Treacy and Faulkner (2015) found that students' basic mathematical skills on entry to third level education, 
between 2003 and 2013, had declined. This research therefore included students' pre and post the introduction of the new curriculum at second level demonstrating that in the initial stages of the introduction of PM students basic mathematical skills were still declining. Treacy and Faulkner (2015) however did find some positive outcomes within their research which suggested that students' problem solving skills may have improved over this time period. The tool that was used to measure problem solving skills over time within this research was not extensive enough to make a stronger claim that that.

Additional research carried out by Prendergast et al., (2017) looked into lecturers' perceptions of the change, if any, in students' mathematical performances post the new curriculum in secondary school being introduced. The findings noted that lecturers' perceived students procedural skills to be getting progressively weaker on entry. However they felt that this was matched with an increased willingness to engage in problem solving activities with unfamiliar problems that was not present with previous cohorts of students beginning their undergraduate studies prior to the introduction of PM.

\section{Literature Review}

Problem Solving in Mathematics

Both educationalist and economists alike have long supported and acknowledged the need and value in having students and citizens who can problem solve in mathematics as well as in the workplace in general (IBEC 2015).

The desire to teach students for understanding so that they can develop the skills necessary to problem solve in a mathematical context has also been documented in the education literature (Perkins 1993). However it has never been deemed a straight forward task to improve teaching instruction and indeed students' ability to problem solve in a mathematical context. Problem solving has often been likened to the weather; more talked about than it is predicted, controlled or understood (Kilpatrick 1969).

Despite the lack of clear understanding in terms of what exactly constitutes mathematical problem solving and how it can be taught, it is clearly something that is extensively sought after both by employers and higher education institutions (CBI 2006; NCETM 2009; Vordermann et al., 2011; Walport et al 2010). This is partially due to these skills not being at the disposal of many schools leavers (ACT 2006; Toner 2011; Jones et al., 2014). Research also highlights issues around students' ability to transfer the mathematical skills they have mastered in their formal education to work place situations or for the study of further mathematics (Treilibs 1979). Many countries, such as Ireland, are therefore attempting to change their mathematics curricula at second level education in an attempt to overcome such issues and ensure that students are developing the necessary problem solving skills for success in further study and future work (OECD 2009; QCA 2008; Rocard 2007; Soh 2008).

In a mathematical context problem solving can be defined in many different ways and can mean different things depending on the context and culture within which the term is used (Schoenfeld 1992). McClure (2013) highlights this also as she discussed the different ways in which a 'problem' can be defined and as a result the different meanings that 'problem solving' can have. McClure (2013) outlines what she sees as the two extreme ends of the problem solving scale in terms of how it has and can be defined:

1. The less extreme end of the problem solving scale is defined by a focus on solving a set of 'problems' by using an already practiced technique. Generally this involves the teacher introducing a problem along with the technique needed to solve the problem. Students in turn engage in several different problems using this same demonstrated technique. The focus 
of this type of problem solving is to complete a group of similar predictable problems in order to develop a specific skill.

2. The more extreme end of the scale describes problem solving as engaging in real problems through: guessing, discovering, and making sense of mathematics. This description of problem solving is in line with Polya (1945) interpretation in which real problems in the definition do not have to be 'real world' applications necessarily but can be problems within mathematics itself. An important feature of this type of problem solving, which distinguishes it from the first type outlined above, is that the problems have to be non-routine and unfamiliar to the student. To sum up it involves the following:

- Seeking solutions rather than memorising procedures

- Exploring patterns rather than memorising formulas and

- Formulating conjectures, not just doing practice questions.

Although there are many other discussions and interpretations of problem solving the two outlined here give an overview of the two extreme ends of the scale according to existing literature in the area. The next section outlines where the PM curriculum falls in terms of its definition of problem solving.

\section{Irish Second Level Mathematics Education and Problem Solving}

Project Maths and Problem Solving

The Project Maths syllabi outline problem solving in the following way:

"Problem Solving means engaging in a task for which the solution is not immediately obvious. Problem solving is integral to mathematical learning. In day-to-day life and in the workplace the ability to problem solve is a highly advantageous skill. In the mathematics classroom problem solving should not be met in isolation, but should permeate all aspects of the teaching and learning experience. Problems may concern purely mathematical matters or some applied context."

The Irish second level mathematics syllabi therefore intends for teachers (and other stakeholders) to view problem solving in line with Polya's (1945) interpretation of it. The curriculum could therefore be seen to have moved from a focus on problem solving which aims to solve a set of 'problems' by using an already practiced technique (McClure 2013) to that which is outlined by Polya (1945) in which students are to engage with real problem solving with unfamiliar problems through guessing, discovering and making sense of mathematics.

The Programme for International Students Assessment (PISA) (2012) technical report details how its aim was to place emphasis "on everyday problem situations that often arise when interacting with an unfamiliar device (such as a ticket vending machine, air-conditioning system, or mobile phone) for the first time" (OECD 2014; p.34). The Project Maths curriculum can therefore also be linked to PISA and its theoretical underpinnings when it comes to developing questions for and assessing problem solving within the second level curriculum. The PISA report also states that it aims to examine what students can reproduce in addition to what they can extrapolate from and apply mathematics to unfamiliar situations (OECD 2014).

The theoretical underpinnings of Project Maths can therefore be aligned with aspects of PISA andPolya's (1945) conceptions of problem solving. Bearing this in mind the next section outlines the means through which problem solving was measured within this research. 


\section{Methodology}

\section{Diagnostic Testing: Measuring Problem Solving}

The tool used to measure students problem solving and procedural skills in mathematics was a diagnostic test (see Appendix 1). The pilot of this tool involved testing students' skills on entry to undergraduate education as well as on entry to an access foundation programme both based in the $\mathrm{X}$ institution, Ireland. The access foundation programme is a one year preparatory programme which upon successfully completion allows students to gain access to undergraduate education. It aims to support students from lower socio economic backgrounds who are often mature and have been out of formal education for many years (Note: a mature student can be defined as any students who is 23 years of age or older (Citizen Information board 2014)). All students tested within this preliminary research were either at the beginning of an engineering undergraduate programme or planning on pursuing an engineering undergraduate programme the following year (access students). Internationally, diagnostic testing is used to measure undergraduate students' skills on entry to higher education (Lawson 1997; Faulkner et al., 2010; Malcolm and McCoy 2007). This type of testing allows an institution to profile an incoming cohort of students in terms of mathematical strengths/weaknesses as well as providing information in terms of what mathematics remediation may be needed to support particular students to be successful.

\section{The Instrument: How was the Diagnostic Test Designed?}

The diagnostic test was designed by four mathematics educators across two higher education institutions in Ireland. The test was designed to compare students' problem solving skills with their procedural skills. The test was piloted using students beginning their undergraduate studies in/aiming to begin their undergraduate studies in an engineering focussed programme. When the test was designed a number of controls were used to ensure that it was fit for purpose. All of these controls enabled the design team of four to determine suitable questions for the diagnostic test. For instance the prototype of the test was critically examined by five mathematics education specialists from universities around Ireland and the feedback from this was incorporated into the test. The procedural and problem solving questions on the test were almost exclusively selected from the Project Maths curriculum so that performance in each section of the test is being examined according to what the Project Maths development team have deemed problem solving to be and not any other interpretation of problem solving.

\section{What does the Diagnostic Test consist of?}

The test is divided into two sections: Procedural questions (Section A) and problem solving questions (Section B). Both sections consists of 9 questions with 2 questions having a part (a) and (b) (11 question in total). Each question in section A of the test is paired with a question in section B i.e. the paired questions require the same procedural skill(s) to successfully complete them with the section B questions also involving some real world context. All of the section B questions have been taken from past Junior and Leaving Certificate examinations from both the ordinary and the higher level courses. The Junior and Leaving Certificate examinations are the formal assessments students sit in their second level education after 3 and 5 years respectively. Students are offered mathematics at Junior and Leaving Certificate at three different levels of difficulty; foundation level, ordinary level and higher level. Problem solving in this case is therefore as per the PM interpretation of the concept in an examination paper context.

\section{Data Analysis}

All data from the diagnostic tests were analyzed using Statistical Package for Social Sciences (Version 22.0) in each section A and B of the diagnostic test. Independent samples t-tests were used to test for statistically significant differences between the mean performances of participants with different 
demographic backgrounds. Chi-Squared tests were used to test for statistically significant associations between the qualitative variables. A 5\% level of significance was used for all tests and no adjustments were made for multiple testing.

\section{Respondents}

Within this pilot study 87 students undertook the test. Of these students $34.5 \%$ (30) were access foundation programme students and $65.5 \%$ (57) were first year undergraduate students enrolled in an engineering programme.

\section{Findings}

Students mean performance in each section of the diagnostic test were examined and results found that the entire group (access and engineering) performed statistically significantly better in the section A $(\bar{x}=57.2)$, the procedural section, when compared to section B, the problem solving section, of the test $(\bar{x}=32.3)(\mathrm{p}<0.001)$.

A comparison of the performance of access against engineering students was also carried out to see if there were significant differences in their performance in each section. This revealed that engineering students performance was statistically significantly better in both sections of the paper when compared with access students $(\mathrm{p}<0.001)$. This is somewhat expected as the access students have been out of formal education for many years.

Further analysis of the engineering students exclusively showed that they performed statistically significantly worse in section B $(\bar{x}=39.5)$ of the test when compared to section A $(\bar{x}=64.6)(\mathrm{p}<0.001)$. The same analysis was carried out on the access students only which revealed that access student also performed statistically significantly worse in section B $(\bar{x}=18.7)$ of the diagnostic test when compared to section $\mathrm{A}(\bar{x}=43.1)(\mathrm{p}<0.001)$.

An analysis of performance by gender found that the mean values for male performance was higher than females performance in both sections of the test, with the differences in mean performance being statistically significantly different for section B, the problem solving section, of the test only $(p<0.05)$. Statistically significantly poorer performances were found for international students in both sections of the test $(\mathrm{p}<0.001)$ when compared with Irish students. Both Irish and International students performed poorer in section B of the test compared to section $\mathrm{A}$.

\section{Discussion}

All categories of students performed statistically significantly worse in section B (i.e. the problem solving section) when compared to section A (the procedural section of the test). Engineering students who were male and Irish were more likely to perform better in the diagnostic test than any other student. However even this cohort of students performed statistically significantly worse in the problem solving section of the diagnostic test when compared to the procedural section of the test.

These findings demonstrate that students have difficulty with applying basic mathematical concepts to applied scenarios. This is despite the fact that the concepts required in the paired questions are exactly the same. For example Q5 in section A requires students to calculate the difference in area between a circle and a rectangle while the paired question in section B asked students to see how much of a rectangular pool area is taken up by a circular jacuzzi contained in the rectangular pool. Students performed statistically significantly worse in section B than A.

Such examples raise questions about how students are adapting to learning mathematics which is not solely based on procedural skills and involves some level of real world thinking and 
contextualisation. Research has indicated that engineers are graduating with good knowledge of fundamental engineering science and computer literacy but little ability to apply this in practice (Mills and Treagust 2003). It appears from this preliminary research that such graduates are entering undergraduate education with a poor ability to apply their mathematical knowledge also. This may suggest that the potential issues occurring in second level mathematics education may also be present in third level mathematics education.

\section{Conclusions and Recommendations}

Although initial studies into PM have indicated that students' problem solving skills may have improved in recent years (Treacy and Faulkner 2015) and that lecturers perceive students as being more open to engaging with unseen maths problems (Prendergast et al 2017), this research indicates that students ability to apply basic mathematical concepts to solve problems is not as strong as their procedural ability when comparing the same concepts.

Although more longitudinal research is needed in this area to make more definite conclusions and recommendations, this preliminary research suggests that more investment is needed in developing students' problem solving ability so that they can successfully engage with mathematics in contexts that require more than just procedural fluency.

Engineering programmes as well as access education in which students are hoping to go onto engineering programmes need to work on producing graduates who are able to adapt and apply their learning. In order for this outcome to be achieved, improvements in the ability of students to problem solve upon entry to higher education is needed. A focus should therefore be placed on second level mathematics improvements in addition to an examination of a mathematics education system in third level which should complement such second level improvements.

\section{References}

ACT., (2006). Ready for College and Ready for Work: Same or Different? Iowa: American College Tests, INC.

American Society of Engineering Education., (1994). The Green Report: Engineering education for a changing world. ASEE, Washington DC, (1994).

Citizen Information Board., (2014) “Third level courses for mature students"http://www.citizensinformation.ie/en/education/third_level_education/applying_to_college/third_level_cours es_for_mature_students.html, (accessed $2^{\text {nd }}$ February 2018)

CBI., (2006). Working with the Three Rs: Employers' Priorities for Functional Skills in Mathematics and English. London: DfES.

Faulkner, F., Gill, O., and Hannigan, A., (2014).The role of prior mathematics experience in predicting mathematics performance in higher education, International Journal in Mathematics Education in Science and Technology, 45(5),648-667.

Faulkner, F., Hannigan, A., and Gill,O., (2010). Trends in the mathematical competency of university entrants in Ireland by leaving certificate grade. Teaching mathematics and its Applications, 29(2), 76-93.

Gill, O.,O'Donoghue, J., Hannigan, A., and Faulkner, F., (2010). Trends in Performance of Science and Technology Students (1997-2008) in Ireland. International Journal of Mathematical Education in Science and Technology, 41(3), 323-339.

Hourigan, M., and O'Donoghue, J., (2007). Mathematical under-preparedness: the influence of the pre-tertiary mathematics experience on students' ability to make a successful transition to tertiary level mathematics courses in Ireland. International Journal of Mathematical Education in Science and Technology, 38, 461-476.

Humphreys, J., (2015). Ireland ranks 15th in global league table for maths, science: The Irish Times.

Irish Business and Employers' Confederation., (IBEC) (2015). Entrepreneurial education Policy recommendations to deliver the skills needed for the workplace of the future, Dublin.

Jones, I., Swan, M., and Pollitt, A., (2014).Assessing mathematical problem solving using comparative judgement.International Journal of Science and Mathematics Education,13 (1), 151-177.

Kilpatrick, J., (1969). Problem Solving in Mathematics: Review of Educational Research,Science and Mathematics Education, 39(4), 523-534.

Lawson, D., (1997). What can we expect from A-Level students? Teaching Mathematics and its Applications, 16, 151-156.

Malcolm, R. K., and McCoy, P., (2007). Evaluation of numeracy skills in first year pharmacy undergraduates 1999-2005. Pharmacy Education: International Journal of Pharmacy Education, 7, 53-59.

McClure, L., (2013). Problem Solving and the New Curriculum: Stage: 1 and 2', NRICH Enriching maths.

Mills, J.E., and Treagust, D.F., (2003). Engineering Education, Is Problem-Based or Project-Based Learning the Answer. Australasian Journal of Engineering Education, 3(2),2-16. 
NCETM., (2009). Mathematics Matters: Final Report. London: National Centre for Excellence in the Teaching of Mathematics. OECD., (2009a). PISA 2009 Results: Learning Trends: Changes in Student Performance Since 2000 (Volume V). Paris: OECD Publishing.

OECD.,(2009b). PISA 2009 Assessment Framework: Key Competencies in Reading, Mathematics and Science. Paris: OECD Publishing.

OECD., (2014). PISA 2012 Technical Report: Test Design and Test Development. PISA, OECD publishing, Paris.

Perkins, D., (1993).Teaching for Understanding.The Professional Journal of the American Federation of Teachers, 17(3), pp. 8,28-35. Polya, G. (1945). How to Solve It. Princeton: University Press.

Prendergast, M., Faulkner, F., Breen, C. \&Carr., M. (2017). Mind the Gap: An Initial Analysis of the Transition of a Second Level Curriculum Reform to Higher Education. Teaching Mathematics and its Applications, In-press.

Prendergast, M., andO'Donoghue,J., (2014). Students enjoyed and talked about the classes in the corridors': pedagogical framework promoting interest in algebra. International Journal of Mathematical Education in Science and Technology, 45(6), 795-812.

QCA., (2008). National Curriculum for England 2008. London: Qualifications and Curriculum Authority.

Rocard, M., (2007). Science Education Now: A Renewed Pedagogy for the Future of Europe. Brussels: European Commission (Technical Report No. EUR22845). Retrieved from http://ec.europa.eu/research/sciencesociety/document_library/pdf_06/report-rocardon-science-education_en.pdf

Schoenfeld, A.H., (1992.).Learning to think mathematically: problem solving, metacognition and sense-making in mathematics. In D.Grouws (Ed.), Handbook for Research on Mathematics Teaching and Learning (pp. 334-370). New York: MacMillan.

Soh, C. K., (2008). An overview of mathematics education in Singapore. In Z. Usiskin and E. Willmore (Ed.), Mathematics Curriculum in Pacific Rim Countries (pp. 23-36). Mississippi: Information Age Publishing.

Toner, P., (2011).Workforce Skills and Innovation (OECD Education Working Papers). Paris: Organisation for Economic Cooperation and Development.

Treacy, P., and Faulkner, F., (2015). Trends in Basic Mathematical Competencies of Beginning Undergraduates in Ireland, 20032013. International Journal of Mathematical Education in Science and Technology,46(8), 1182-1196.

Treilibs, V., (1979). Formulation Processes in Mathematical Modelling. Unpublished MPhil, University of Nottingham, Nottingham.

Vordermann, C., Porkess, R.., Budd, C., Dunne, R.., and Rahman-Hart, P., (2011). A WorldClass Mathematics Education for All Our Young People. London: The Conservative Party.

Walport, M.., Goodfellow, J., McLoughlin, F., Post, M., Sjøvoll, J., Taylor, M., \&Waboso, D., (2010). Science and Mathematics Secondary Education for the 21st Century: Report of the Science and Learning Expert Group. London: Department for Business, Industry and Skills 


\section{Appendix A}

\section{Mathematics Education Research Quiz}

\section{Purpose}

The purpose of this quiz is to ascertain whether you are having difficulty with a particular aspect of mathematics. The results of this quiz will be used for research purposes and to ensure that mathematics is being taught in X as per the students' needs.

Formal ethical approval has been sought by the $\mathrm{X}$ research ethics committee.

\section{Important Note}

This is a stand-alone quiz and will not affect any of your module marks in Year 1.

\section{Instructions}

Please fill in the details requested below and proceed to answer the questions. Attempt each question. Calculators are allowed.

Time: 45 mins (approx.) 
To begin, please create a personal identification code that will be used to ensure all questionnaires are anonymous by choosing an answer for each of the options below.

First letter of your first name

Day of the month you were born $(1-31)$

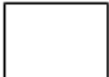

Month you were born (1 = January, 2 = February etc.)

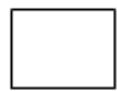

First letter of the county where you were born (Use X if born outside of Ireland)

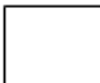

Mature Student: Yes $\square$ No

Gender: Male

Female

Completed X Access Programme: Yes

International Student: Yes $\square$ No

Leaving Certificate Maths

Year of Leaving Certificate

Please tick $(\boldsymbol{V})$ the appropriate grade:

$\square$ Higher $\square$ Ordinary $\square$ Foundation

A1 $\square$ A2 $\square$ B1 $\square$ B2 $\square$ B3 $\square$ C1 $\square$ C2 $\square$ C3 $\square$ D1 $\square$ D2 $\square$ D3 $\square$ other $\square$ Not Applicable $\square$ 


\section{Subject Information Sheet}

Title of the Project: Investigating first year under-graduates/access students' procedural and problem solving skills.

\section{Purpose}

The purpose of this quiz is to ascertain whether you are having difficulty with a particular aspect of mathematics. The results of this quiz will be used for research purposes and to ensure that mathematics is being taught in $\mathrm{X}$ as per the students' needs. Formal Ethical approval has been sought and received from $X$ to carry out this research.

\section{Important Information}

This is a stand-alone quiz and will not affect any of your module marks in Year 1. You are not obliged to take the quiz. If you agree to take the quiz but at a later stage feel the need to withdraw you are free to do so. All results from each quiz will be kept confidential.

\section{Subject Consent Form}

Title of Project: Investigating first year under-graduates/access students' procedural and problem solving skills.

You are under no obligation to participate in this study. If you agree to participate, but at a later stage feel the need to withdraw, you are free to do so. It will not affect you in any way.

\section{Please answer all of the following (tick the appropriate box):}

\section{Yes No}

I have read and understand the subject information sheet.

I understand what the project is about and what the results will be used for.

I know that my participation is voluntary and that I can withdraw from the project at any stage without giving any reason.

I am aware that my results will be kept confidential. 


\section{Section A}

Rough Work

1. Find the mean of the following numbers: $8,9,9,7,3,3,12$

Ans:

2. (a) Detail how many different ways the following 6 numbers can be arranged: $2,8,6,4,9$ and 7 .

Ans:

(b) From the numbers in part (a) above one arrangement of numbers is picked at random. What is the probability that this arrangement begins with the number 6 ?

Ans:

3. Solve the following triangle for $x$ :

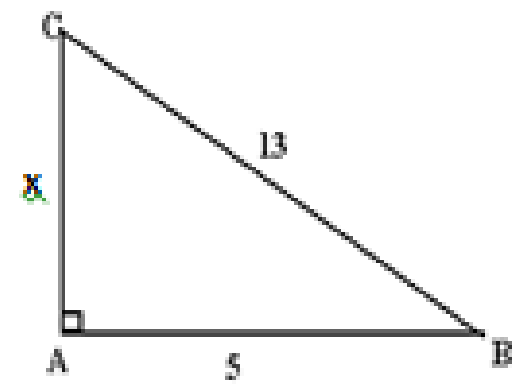

Ans:

4. What is the difference in the areas of: a circle with radius $5 \mathrm{~cm}$ and a rectangle with a length of $12 \mathrm{~cm}$ and a width of $10 \mathrm{~cm}$ ?

Ans:

Note: Area of a circle $=\pi r^{2}$ where $\pi=3.14$.

5. What is the percentage decrease from the number 70 to 60 ?

Ans:

6. Divide 150 into a ratio of 5:4:1.

Ans: 


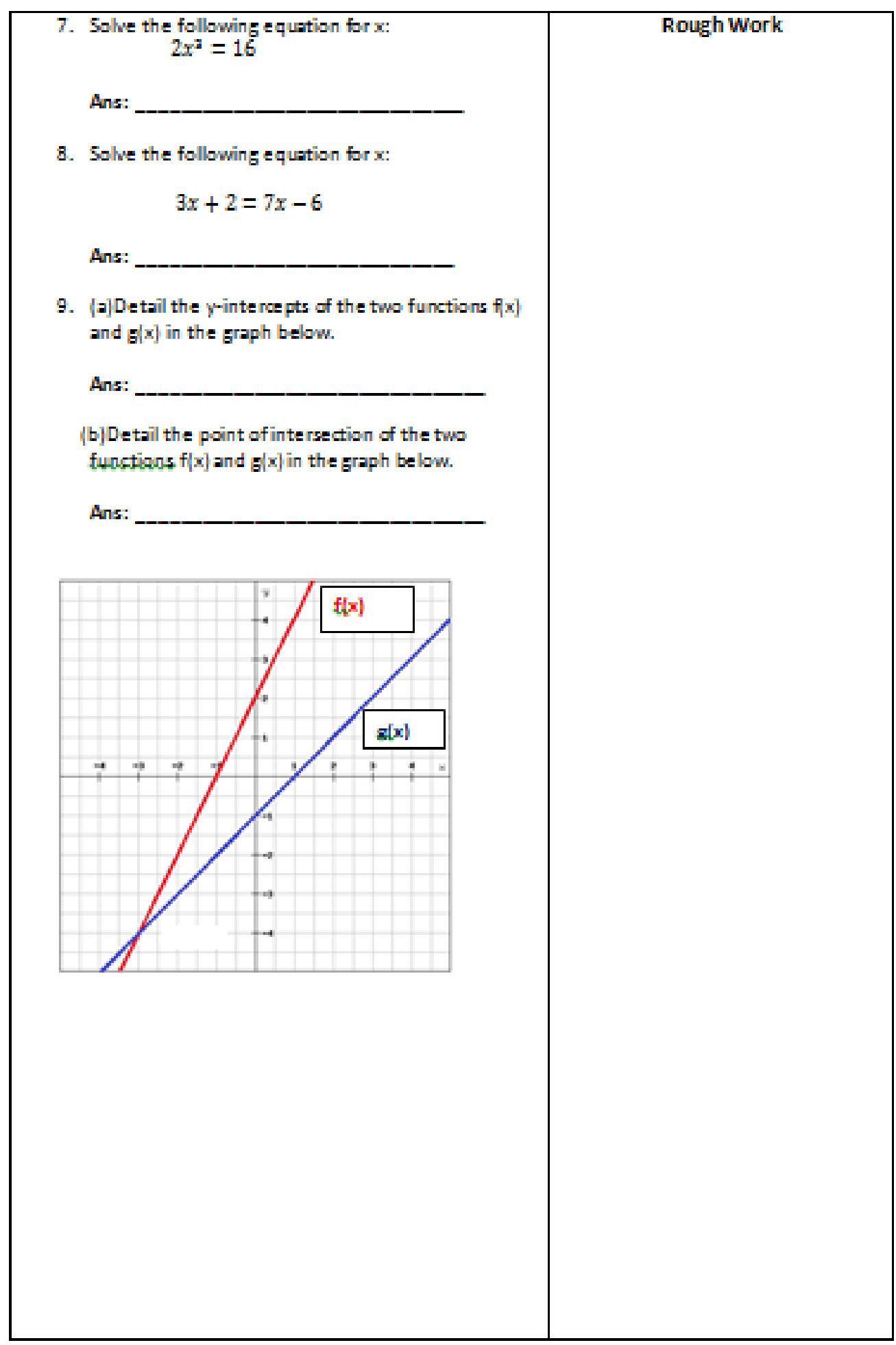




\section{Section B}

1. The number of new cars sold every three months in 2015 in a garage in Dublin is given in the table below:

\begin{tabular}{|l|l|}
\hline Month & Cars Sold \\
\hline Jan-March & 300 \\
\hline April-June & 150 \\
\hline July-Sept & 210 \\
\hline Oct-Dec & 75 \\
\hline
\end{tabular}

Calculate the mean number of cars sold per month in 2015. Ans:

2. A bank issued a 6 digit pin to each of its customers. The pin number may contain any numbers from $0-9$ and numbers can be repeated. For example the following pin number is acceptable:

\begin{tabular}{|l|l||l||l|l|l|}
\hline 4 & 2 & 7 & 6 & 7 & 0 \\
\hline
\end{tabular}

i. How many different 6 digit pin numbers are possible?

Ans:

ii. One pin number is selected at random. What is the probability that this pin number contains at least one 0 ?

Ans:

3. Joan, who is at $T$, is playing golf and attempts to hit the ball towards the hole at $H$. The ball goes off course and lands at $A$. What straight-line distance does that ball need to travel from the point it is at now to the hole? (HL LC 2015 P2).

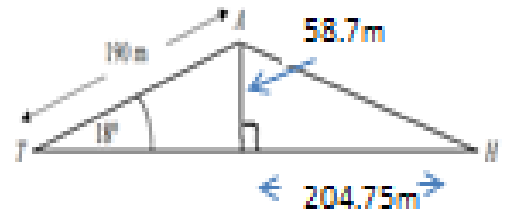

Ans: 
4. A swimming pool of length $15 \mathrm{~m}$ and width $8 \mathrm{~m}$ had a circular Jacuzzi of radius $2 \mathrm{~m}$ put into it. How much of the surface area of the swimming pool will be left when the Jacuzzi is introduced? (HL JC 2015 P2).

Ans:

Note: Area of a circle $=\pi r^{2}$ where, $\pi=3.14$.

5. Sean weighs $90 \mathrm{~kg}$. The average male weight-lifter of his height is usually $110 \mathrm{~kg}$. What percentage increase in body weight would Sean need in order to reach his desired weight of $110 \mathrm{~kg}$ ? Give your answer correct to 2 decimal places. (HL JC2015).

Ans:

6. Cormac, Mark and Michael bought a ticket for the EuroMjlipgs, between them. The tidket cost 660 . Cormac paid $€ 25$ towards the ticket, Mark paid $€ 20$ and Michael paid 615 . The ticket won a prize of 6100,000 and they divided the prize up in proportion to how much each of them paid. How much prize money does each person receive? jOL LC 2015).

Ans:

7. A company has a tank with a cylindrical centre and hemispherical ends. The volume of one hemispherical end is $190.85 \mathrm{~m}^{2}$. Find the radius of one of the hemispherical ends (LC OL 2015). Note: Volume of hemisphere; $V=\frac{2}{2} \pi r^{2}$ where, $\pi=3.14$.

Ans:

8. Amanda buys a car for 625,000 . On the day that Amanda bought her car, Cathal also bought a new car. His car cost 622,500 . Amanda's car will travel 15 $\mathrm{km}$ on a litre of fuel. Cathal's car will travel $10 \mathrm{~km}$ on a litre of fuel. How many kilometres will the cars have to travel until the cost price of the car plus the cost af fuelare, equal, for the two cars? Assume thet fuel costs 61.50 per litre over the period (OL LC P1 2015).

Rough Work

Ans: 


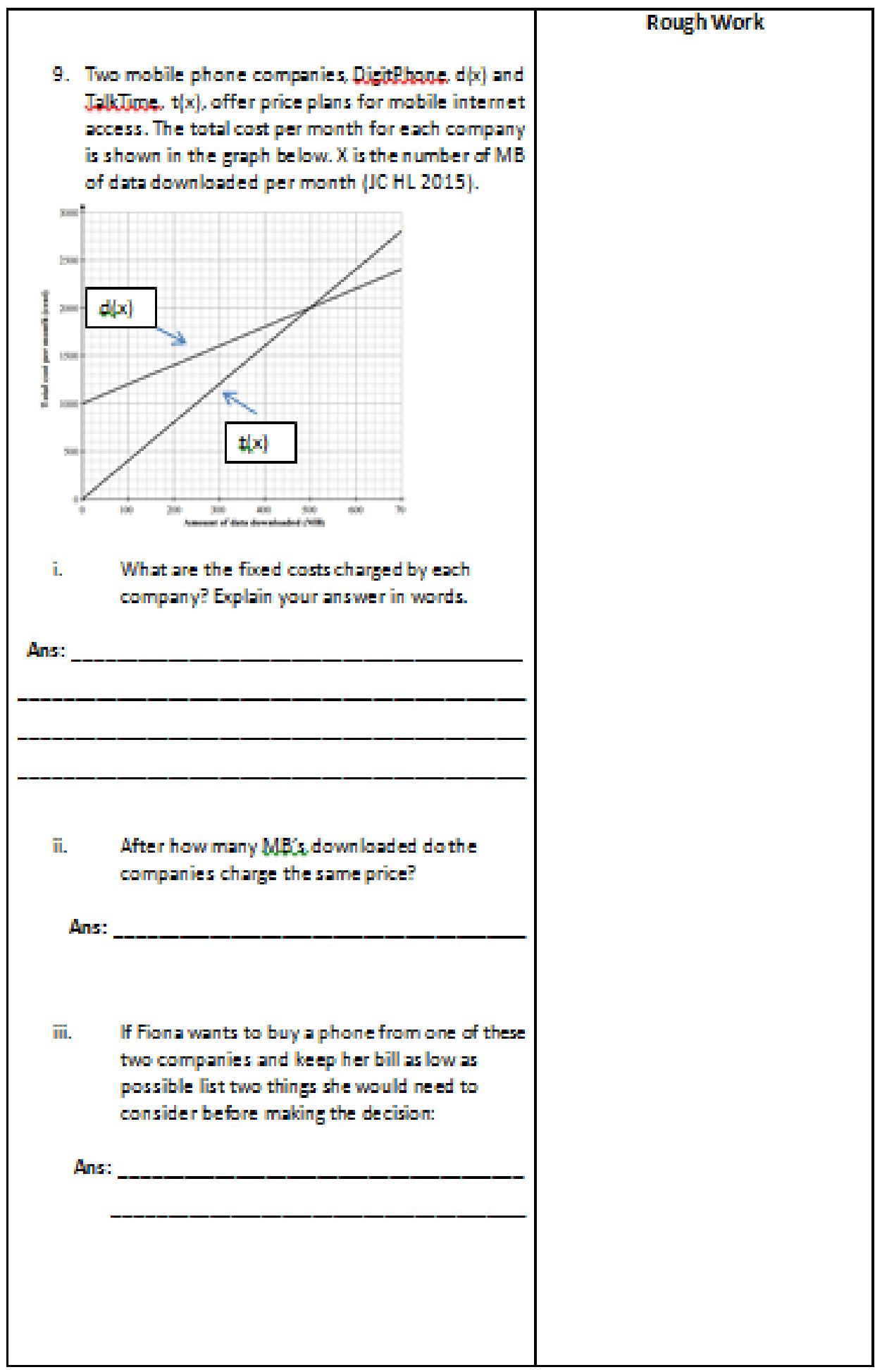

